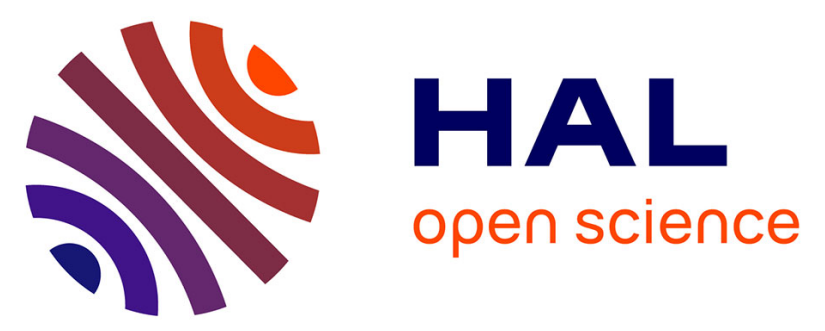

\title{
Autonomous vehicles: scientometric and bibliometric review
}

Rodrigo Marçal Gandia, Fabio Antonialli, Bruna Habib Cavazza, Arthur

Miranda Neto, Danilo Alves De Lima, Joel Yutaka Sugano, Isabelle Nicolaï, André Luiz Zambalde

\section{To cite this version:}

Rodrigo Marçal Gandia, Fabio Antonialli, Bruna Habib Cavazza, Arthur Miranda Neto, Danilo Alves De Lima, et al.. Autonomous vehicles: scientometric and bibliometric review. Transport Reviews, In press, pp.1 - 20. 10.1080/01441647.2018.1518937 . hal-01877042

\section{HAL Id: hal-01877042 \\ https://hal-centralesupelec.archives-ouvertes.fr/hal-01877042}

Submitted on 4 Oct 2018

HAL is a multi-disciplinary open access archive for the deposit and dissemination of scientific research documents, whether they are published or not. The documents may come from teaching and research institutions in France or abroad, or from public or private research centers.
L'archive ouverte pluridisciplinaire HAL, est destinée au dépôt et à la diffusion de documents scientifiques de niveau recherche, publiés ou non, émanant des établissements d'enseignement et de recherche français ou étrangers, des laboratoires publics ou privés. 


\title{
Autonomous Vehicles: Scientometric and Bibliometric Review
}

\author{
Rodrigo Marçal Gandia ${ }^{1,2}$ - Fabio Antonialli ${ }^{1,2,3}$ - Bruna Habib Cavazza ${ }^{1,2,3}$ Arthur \\ Miranda Neto ${ }^{2,4}$ • Danilo Alves de Lima ${ }^{2,4}$ • Joel Yutaka Sugano ${ }^{1,2}$ • Isabelle Nicolai ${ }^{3}$. \\ Andre Luiz Zambalde ${ }^{1,2}$
}

\begin{abstract}
This paper presents a scientometric and bibliometric review of the research on autonomous vehicles (AVs) to identify its main characteristics, evolution, and potential trends for future studies. Relevant articles were searched on WoS, yielding a research corpus of 10,580 papers, and the software CiteSpace was subsequently used for analysis. The results showed that AV research is heterogeneous and registered a growing demand over time. Multidisciplinarity is present, with 96 science fields being identified. As in any other sector, it is necessary to understand broader aspects of this industry such as the market factors surrounding it, as well as other economic and managerial issues. In this sense, we observed a migration of the research field from multidisciplinarity to pluridisciplinarity with a greater number of studies focusing on the latter. We understand that terminology standardization contributes to achieving pluridisciplinarity. As such, it is important to highlight that sustainability, public policies, liability, and safety, as well as business issues such as performance and business models are some of the tendencies in the field of AVs. For future studies, we suggest a more in-depth analysis of publications in terms of individual search terms, as well as the sub-areas identified as trends in this paper.
\end{abstract}

Keywords Autonomous Vehicles $\bullet$ Bibliometrics $\bullet$ Scientometrics $\bullet$ Review $\bullet$ CiteSpace

\section{Introduction}

The robotics industry has been contributing to many everyday aspects for over five decades. Further, several IT-related industries based on mobile information technology are emerging due to the second information revolution, which is also called the fourth industrial revolution (Rifkin, 2011; Schwab, 2017). In this context, the first vehicle equipped with an automated driving system appeared in the mid-1980s at Carnegie Mellon University, the Navlab 5 (Pomerleau \& Jochem, 1996). Since then, several advances have been made in this area, and numerous major companies and research organizations have developed autonomous vehicle $(\mathrm{AV})$ prototypes.

There is a strong expectation that AVs could be used to provide accessibility to people in need, reducing the costs and time of transportation systems, and offering comfort to people who do not (or cannot) drive (Mutz et. al., 2016). Although the reality of AVs may

Rodrigo Marçal Gandia - romgandia@gmail.com

${ }^{1}$ UFLA - Universidade Federal de Lavras, Programa de Pós-Graduação em Administração, Lavras - Minas Gerais, Mailbox 3037 - CEP 37200-000, Lavras, Brazil.

${ }^{2}$ LMT - Terrestrial Mobility Laboratory, Universidade Federal de Lavras, Engineering Department DEG/UFLA Mailbox 3037 - CEP 37200-000, Lavras, Brazil.

${ }^{3}$ CentraleSupélec/Université Paris-Saclay, LGI - Laboratoire Génie Industriel, 9 rue Joliot Curie

- 91190 Gif-sur-Yvette, France.

${ }^{4}$ UFLA - Universidade Federal de Lavras, Departamento de Engenharia, Lavras - Minas Gerais, Mailbox 3037 - CEP 37200-000, Brazil. 
seem distant, it is increasingly evident their progress and arrival is highly likely in the near future (Attias, 2017).

The automated driving technology is changing rapidly due to road safety concerns, potential cost savings, and technology innovations (McKinsey \& Company, 2016). The current technology state, along with expected improvements and the already-announced plans of several large Original Equipment Manufacturers (OEMs) and others, make it likely that AVs will be available by the mid-2020s. In the business context, AVs have been gaining increasing attention, as numerous companies have been standing out in the "race" for leadership in this innovation process.

Although the AV theoretical field has been established, its main aspects, conceptual base, tendencies, and characteristics have not been fully identified yet. Consequently, the following questions emerged as a framework for this paper: (i) how does the field of studies regarding AVs perform; (ii) what is the historical evolution of the field (science branches and fields of knowledge); and (iii) what are the thematic of the technological evolution and the main research trends?

In this sense, we carry out a scientometric and bibliometric review to identify the main characteristics of the AV field, as well as its evolution and to highlight the potential trends for prospective studies.

Our paper is structured as follows. Section 1 provides an overview of AVs with respect to their concept and terminologies, assumed benefits/implications, as well as the efforts of different stakeholders to promote these vehicles. Section 2 presents the research methodology, explaining the necessary steps to perform the scientometric technique. Section 3 presents the results and discusses the proposed analysis in two stages: a descriptive analysis of the papers, seeking to delineate the field of study, and insights to researchers in the field of AVs by an in-depth analysis of the conceptual base, trends, directions, and changes that are influencing this research area. Finally, in Section 4, we present concluding remarks, summarizing the main findings and highlighting the possibilities for future research.

\section{Autonomous Vehicles Overview}

AVs are cars with motion and action capabilities that do not require any sort of conductor (driver) or teleoperation control (Frazzoli, Dahleh \& Feron, 2002). The Society of Automotive Engineers (SAE, 2016) has recommended the term "automated driving systems (ADS)" to refer to vehicles with different automation levels to avoid multiple definitions with ambiguous meanings. The aim of this terminology is to encompass several terms widely used in the literature, such as: autonomous vehicles/cars, self-driving cars, carlike robots, intelligent vehicles, driverless cars.

AVs represent a potentially disruptive and beneficial change to the intelligent transportation systems business model, as pointed out by Milakis, Van Arem, and Van Wee (2017), as automated driving might bring several interrelated effects to mobility and society. The authors refer to such implications such as the "ripple effect," in which AVs are placed in the center and surrounded by a first layer of implications, such as traffic, travel cost, and travel choices, while a second layer implies changes in vehicle ownership and sharing, location choices and land use, and transport infrastructure. Finally, the third layer refers to wider societal implications due to the introduction of AVs, such as energy consumption, air pollution, safety, social equity, economy, and public health.

On the other hand, AV proliferation is far from guaranteed. As Fagnant and Kockelman (2015, p. 168) state, "complex questions related to legal aspects, liability, privacy, licensing, 
security, and insurance regulation still remain to be solved." Further, AVs may introduce new risks, such as system failures that would make these vehicles less safe under certain situations and conditions due to being connected to the cloud and operated by a central unit system, also meaning there will be security and privacy concerns related to cyber security.

Further, Hucko (2017) highlights that the abuse of vulnerable information, tracking, and data sharing could violate passengers' privacy, and that such cars could be used for terrorist activities. The high costs related to additional car equipment services and maintenance, as well as further investments in roadway infrastructure, would hamper large-scale production and mass consumer availability (KPMG \& CAR, 2012; Grau, 2012; Hickey, 2012).

Autonomous technology is now the greatest bet of large automakers, led in the United States by Ford, GM, and Tesla and in Europe by Audi, Mercedes, and Volvo, as well as California technology giants such as Google and Uber (Nascimento, Salvador \& Vilicic, 2017). According to the authors, Google's AVs (Waymo) have reached the mark of more than 5 million kilometers driven on American avenues, streets, and roads, while Uber's AVs have also reached over 1.5 million driven kilometers in their testing cities of Pittsburgh, Phoenix, and Toronto.

Meanwhile, numerous carmakers, such as Audi, BMW, Cadillac, Ford, GM, MercedesBenz, Nissan, Toyota, Volkswagen, and Volvo, are already testing AVs (Fagnant \& Kockelman, 2015), not to mention that vehicles with semi-autonomous capabilities at the Society of Automotive Engineers' (SAE, 2016) level 2 and 3 of automation are already being marketed (e.g., Tesla's Roadster, Model S, Model X, Mercedes-Benz's S65, Infiniti's Q50S, BMW's 750i xDriv for SAE's level 2 and Audi's A8, which according to Nascimento, Salvador, and Vilicic (2017), is the first mass produced vehicle to have a level 3 embedded autonomous driving system).

Also worth mentioning are the partnerships among companies, which have been a common method for the development and advance of new AVs technologies (e.g., BMW's alliance with Intel and Mobileye) and even for training new professionals in the field, such as the partnership among Mercedes Benz, McLaren, Otto, Nvidia, and Udacity (University of the Silicon Valley) to create an online course for training engineering professionals in the area.

The governments of several countries have also become interested in the possible benefits of vehicular automation. The United States was the first country to introduce legislation allowing the testing of AVs on their streets and roads. The same goes for several European countries (e.g., Finland, France, Germany, Italy, the Netherlands, Spain, Sweden, and the UK), where lawmakers are already allowing the development and testing of AV technologies on their roads as well (Patel, 2018). Similarly, Asian countries such as Japan, Singapore, China, and South Korea are interested in international regulations being updated to allow for the development of automated vehicle technologies (Schoitsch, 2016; U.K. Department for Transport, 2015).

Significant advances are also being made within academia, as pointed out by Cavazza et al. (2017), Lima (2015), Weick and Jain (2014), as research centers and universities worldwide are striving to advance studies on technology mobility, vehicle-infrastructure interaction, and management and business-related issues for the consolidation of autonomous vehicles.

According to Yun et al. (2016), the advancement of technological innovations in the AV field is part of the dynamic relationship established between technology, business model, and market. In this context, the possibility of changes in the dynamic relationships between these three factors to obtain the expected results is evident. This change may be part of a process inherent to the role of a business model not yet established. However, in the future, it will be necessary to develop dynamic system models and more concrete simulation 
research on political leverage, including the market's growth pattern and the implications it will have on multiple sectors.

There are several contributions on the subject, and the transition from a long-established industry (automotive) to a new configuration (mobility eco-system) is still surrounded by uncertainties as to the inherent aspects of regulatory factors, technology, business models, and market. Through the investigation and map of this field's main features, a bird's eye view of the current research can contribute to the field.

\section{Research Methodology}

This study was conducted from November 2016 to February 2017 and updated during May-July 2018. It is descriptive and also employs a quantitative approach to identify the main characteristics of the AV field, as well as its evolution to highlight potential trends for future studies. The research is characterized as scientometric and bibliometric, based on articles indexed in the Thomson Reuters' Web of Science (WoS) database.

The scientometric technique, which is a method that refers to knowledge domain visualization or mapping (Pollack \& Adler, 2015) and a quantitative technique that applies bibliometrics to published literature (Börner, Chen \& Boyack, 2003) is used to map the structure and evolution of numerous subjects based on a large-scale scholarly dataset through network modeling and visualization. Scientometric research aims to analyze the intellectual landscape of a knowledge domain and perceive questions that researchers have been attempting to answer, as well as the methods they have developed to achieve their research goals (Chen and Paul, 2001).

Bibliometric analysis must be systematic and stem from primary studies; it must also comprise the aims, as well as clearly expressed materials and methods and be conducted through a clear and reproducible methodology (Greenhalgh, 1997). In this sense, the results of bibliometric analysis are useful for: 1) measuring and understanding the study field of a given subject; 2) providing a solid view of the field's historical evolution; 3) presenting a thematic and technological analysis; and 4) providing evidence and a basis for future research.

Based on these methodological procedures, the present study proposes four steps, which are described in the following and illustrated in Figure 1.

- Step 1 - Delimitation of analysis scope and article selection: the articles were searched on the WoS database in a single search, from 1945 to 2018, using the Boolean operator $^{5}$ "OR." Because of the multiples definitions still used in this field, the papers were selected using the following terms in the title, abstract, or keyword fields: autonomous_car; autonomous_vehicle; autonomous_automobile; automated_car; automated_vehicle; automated_automobile; driverless_car; driverless_vehicle; driverless_automobile; selfdriving_car; self-driving_vehicle; self-driving_automobile; intelligent_car; intelligent_vehicle; intelligent_automobile; and automated_driving_system. This search resulted in 10,580 results, which constitute the corpus of the present study.

- Step 2 - Descriptive analysis of papers: the following analyses were performed: 1) number of papers published per searched term; 2) number of papers per year; 3) most published authors; 4) most published sources; and 5) countries analyzed.

\footnotetext{
${ }^{5}$ The Boolean operator underline ', ' was used to ensure the search yielded only the results in which the pair of words appeared together. Terms were only searched in the singular form, as this would find both singular and plural terms.
} 
- Step 3 - In-depth analysis of papers: we carried out on CiteSpace the following indepth analysis of the 10,580 articles: 1) dual-map overlay; 2) analysis of the main WoS categories in which the articles were published; and 3) analysis of the most relevant keywords.

- Step 4 - Interpretation and discussion of results: we carried out a joint interpretation and discussion of the results in steps 2 and 3, to identify the main research trends and gaps within the fields of study.

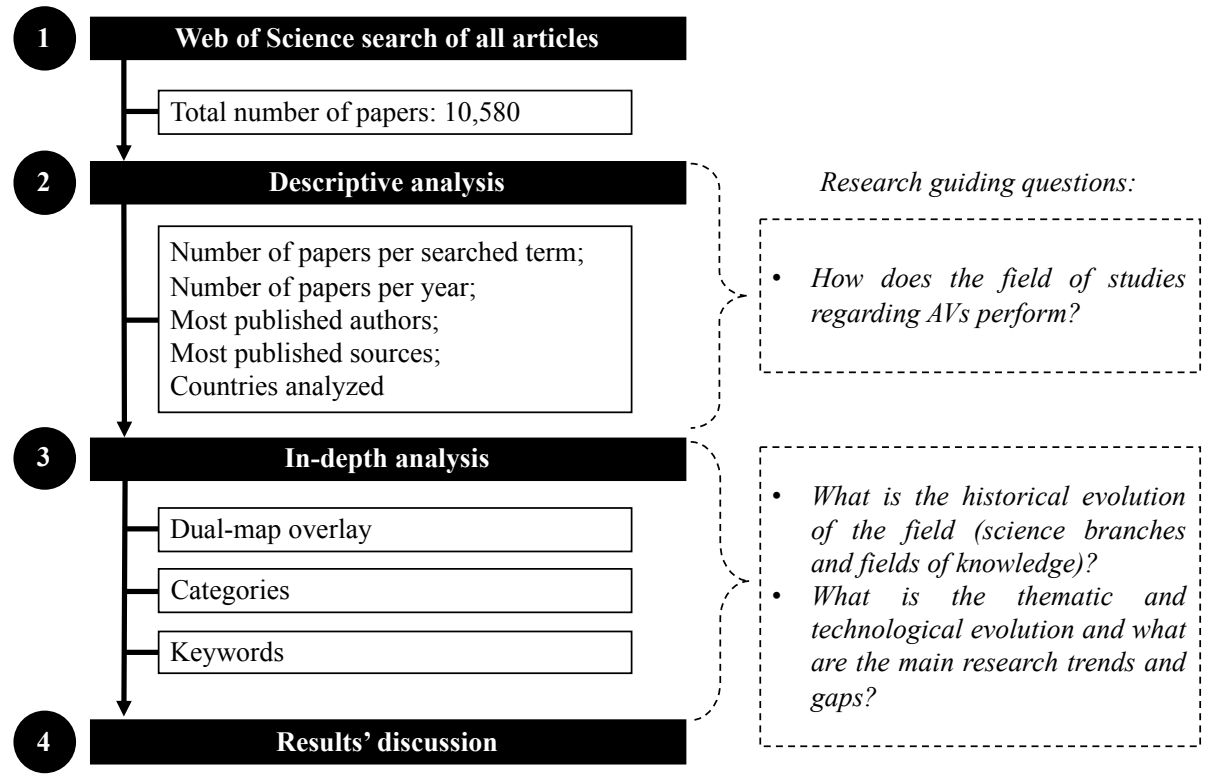

Fig. 1: Methodological research design.

Source: prepared by the authors.

\section{Results and discussion}

The results and discussion of the proposed analysis are presented in two stages. The first one presents a descriptive analysis of the papers, seeking to delineate this field of study. The second stage is characterized by an in-depth analysis of the theme to draw a thematical and technological evolution of the field, as well as point out the main research trends and gaps.

\section{Descriptive analysis}

To separately observe the contribution of each searched term used to create the sample for this study, Figure 2 illustrates the number of papers, as well as the year of publication of the first paper by each searched term.

The terms "autonomous_vehicle" and "intelligent_vehicle" were the most representative, yielding 6,087 and 2,310 papers, respectively. In this sense, it is possible to infer the relevance of the term "autonomous_vehicle" to the research field in detriment to the other possible terminologies. On the other hand, the term "driverless_car" yielded the oldest record in the sample, having the first paper published in 1969.

In 2014, SAE adopted the terminology of ADS to refer to vehicles with different automation levels and avoid multiple definitions with ambiguous meanings (SAE, 2014, 2016). The term "automated_driving_system" was first used in a publication in 1997; 
however, it is important to highlight its evolution in terms of publication number, in that the average until 2014 was 2.2 papers per year and increased to 31.6 papers per year from 2015 . It is worth noting that, although being the official recommendation of SAE, the term ADS represents only $1.12 \%$ (118 papers) of the total sample (10,580 papers).

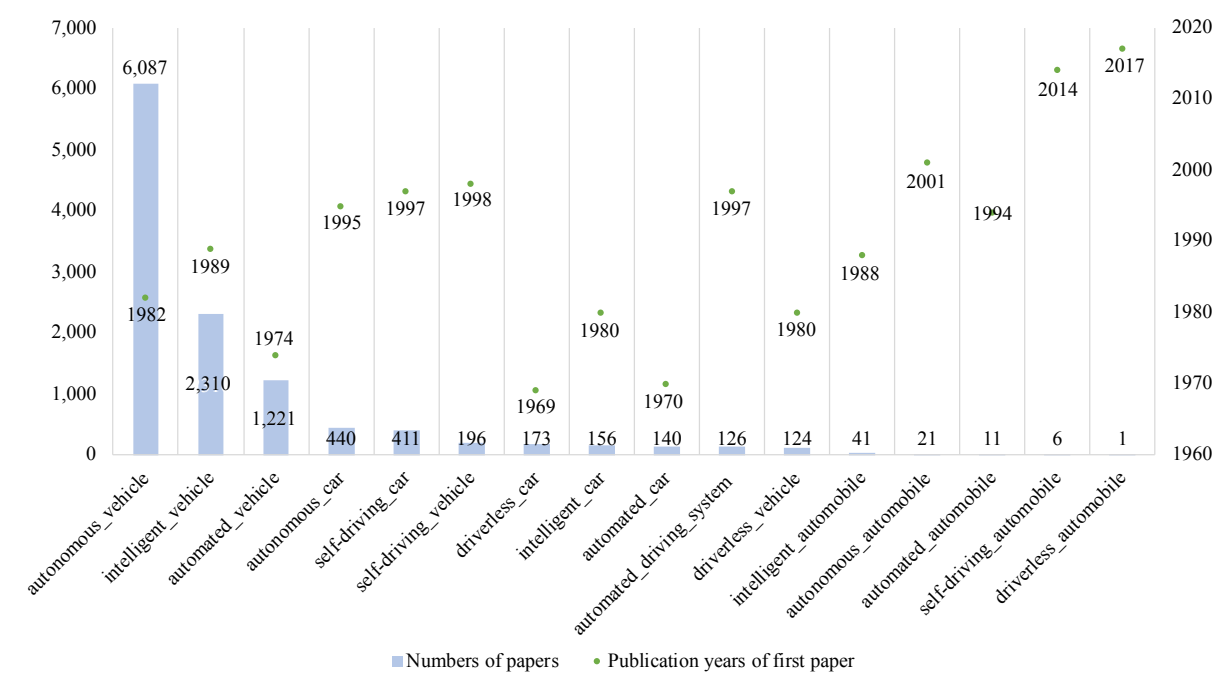

Fig. 2: Number of papers per searched term Source: prepared by the authors

The temporal distribution of the 10,580 papers published on the subject of AVs began in 1969 with Palatnick and Inhelder's work. The uninterrupted evolution of AV publications began in 1982 with the work of Roberts and Mathews (1982) and, from there, it followed an exponential curve (Figure 3), the years 2016 and 2017 registering the greatest number of publications of 1,379 and 1,856 papers, respectively.

Figure 3 also shows the publication trend line for the AV field, in which from 1969 to 2011 , the number of publications followed the trend line with slight ups and downs (except for 1999, which showed a larger decline). However, from 2012, the number of publications exceeded the trend line, showing an exponential growth of the field in recent years. Compared to the average science growth rate, which is around $8-9 \%$ per year according to Bornmann and Mutz (2015), the related average growth rate of publications on AVs was $39 \%$ over the analyzed period.

This growth may indicate the publications in several AV related areas as its introduction to the market approaches, with several implications for all sectors of the economy. 


\begin{tabular}{|l|}
\hline E Number of papers/year \\
- Publications' trend line \\
\hline $\begin{array}{l}\text { - Science average growth rate: } 8 \% \text { to } 9 \% \\
\text { (source: Bornmann \& } M u t z, 2015)\end{array}$ \\
- AV's average growth rate: $39 \%$ \\
(source: research data)
\end{tabular}

* when data was collected, the year 2018 had not yet finished.

Fig. 3: Number of papers per year based on WoS data.

Source: prepared by the authors.

The top five authors with most publications are Junsoo Kim (49), Vicente Milanes (46), Umit Ozguner (46), Javier Perez (45), and Alberto Broggi (44). Nonetheless, there is significant heterogeneity when it comes to the most published authors. Based on WoS results, we observed 20,314 authors were responsible for the 10,580 papers.

From this result, a parallel with Price's Elitism Law (1976) can also be made. We observe that the elite corresponds to 143 authors $(\sqrt{10,580})$, who are responsible for 3,157 out of the total 10,580 identified papers. This value is below the minimum considered by the elitism law, assuming that for being considered a productive elite, these 143 authors should have published approximately 5,290 papers (half of the total number of publications). In this sense, we infer that the AV field is still incipient, considering the reduced number of works-per-author, with no existence of a considerable productive elite.

As for the number of publications, we carried out Bradford's Dispersion Law (1934) analysis. In this analysis, there are three distinct zones (nucleus) papers could fit in, each one containing $1 / 3$ of the total of relevant articles.

The first nucleus (described in Table 1) contains 25 distinct sources with a total of 3,526 publications. The second nucleus (larger number of less productive journals) contains 259 different sources, which are responsible for 3,499 publications and, at last, the third nucleus (includes more journals, but each with less productivity), has 3,269 sources, responsible for 3,555 publications. Therefore, we observed that from the 3,553 sources responsible for AV publications, only $25(0.70 \%)$ were responsible for approximately $33 \%(3,526)$ of the field's publications.

Table 1: Top 25 higher publications (first nucleus) of sources in numbers of papers

\begin{tabular}{lc}
\hline IEEE Intelligent Vehicles Symposium & 670 \\
\hline IEEE International Conference on Intelligent Transportation Systems (ITSC) & 498 \\
\hline Proceedings of The Society of Photo Optical Instrumentation Engineers (SPIE) & 322 \\
\hline IEEE Transactions on Intelligent Transportation Systems & 288 \\
\hline Lecture Notes in Computer Science & 169 \\
\hline Proceedings of The American Control Conference & 164 \\
\hline IEEE International Conference on Robotics and Automation (ICRA) & 119 \\
\hline IFAC Papersonline & 111 \\
\hline IEEE Conference on Decision and Control & 104 \\
\hline Transportation Research Record & 98 \\
\hline IEEE International Conference on Intelligent Robots and Systems (IROS) & 92
\end{tabular}




\begin{tabular}{lc}
\hline Transportation Research Part C: Emerging Technologies & 90 \\
\hline IEEE Transactions on Vehicular Technology & 89 \\
\hline Oceans IEEE & 83 \\
\hline IEEE International Conference on Systems Man and Cybernetics Conference Proceedings & 81 \\
\hline Sensors & 79 \\
\hline Robotics and Autonomous Systems & 65 \\
\hline Lecture Notes in Mobility & 59 \\
\hline Lecture Notes in Artificial Intelligence & 58 \\
\hline Control Engineering Practice & 55 \\
\hline Advances in Intelligent Systems and Computing & 50 \\
\hline IEEE Transactions on Control Systems Technology & 50 \\
\hline Applied Mechanics and Materials & 44 \\
\hline IEEE Industrial Electronics Society & 43 \\
\hline International Conference on Connected Vehicles and Expo & 43
\end{tabular}

Source: prepared by the authors.

Table 1 also shows the concentration of sources in the first nucleus that belong to congresses or conferences (62\%). This can be explained by the distribution of works related to AVs, where approximately $66 \%$ are proceedings papers, whereas $34 \%$ are journal articles, which may explain the recent recurrence of AVs in academia. This result also demonstrates that the discussion on AVs is far from being exhausted, characterizing this subject as a trending topic among researchers. It is worth mentioning the Institute of Electrical and Electronics Engineers' (IEEE) eloquence in this field, with 19 occurrences among the components of the first nucleus (51\%). We also highlight that the outputs of this analysis are important to signal the most prominent sources (journals and conferences) that publish studies in this field.

As for countries, Table 2 presents - based on CiteSpace's analysis - the results of the top 20 (of 91) countries that published papers on AVs regarding number of publications, year of first publication, total papers, and centrality. The centrality metric indicates the importance of a given node and its collaboration in a network (Chen et al., 2010; Vasudevan et al., 2016). In other words, the more central the country, the greater the number of publications with other countries. It is important to highlight that a country with high centrality may not necessarily have a high number of publications. For instance, the USA has the highest number of publications $(3,078)$ and a low centrality index $(0.11)$, which indicates that it does not partner with as many countries for publications. On the other hand, England, Spain, Sweden, and others have higher centrality levels than the US although they have significantly fewer papers published.

Table 2 also presents the position of each country based on the KPMG (2018) ranking, which measures the countries' degree of openness and preparedness for AVs on 26 different variables within four pillars (policy and legislation, technology and innovation, infrastructure, consumer acceptance).

\begin{tabular}{lccccc}
\hline \multicolumn{1}{c}{ Countries } & $\begin{array}{c}\text { CiteSpace } \\
\text { Ranking }\end{array}$ & $\begin{array}{c}\text { KPMG } \\
\text { Ranking }\end{array}$ & $\begin{array}{c}\text { First } \\
\text { publication }\end{array}$ & $\begin{array}{c}\text { Total } \\
\text { papers }\end{array}$ & Centrality \\
\hline United States & 1 & 3 & 1986 & 3.078 & 0.11 \\
\hline China & 2 & 16 & 1993 & 1.484 & 0.08 \\
\hline Germany & 3 & 6 & 1992 & 897 & 0.09 \\
\hline France & 4 & 13 & 1994 & 612 & 0.11 \\
\hline South Korea & 5 & 10 & 1998 & 527 & 0.00 \\
\hline Japan & 6 & $\mathrm{n} / \mathrm{a}$ & 1988 & 477 & 0.00 \\
\hline
\end{tabular}




\begin{tabular}{lccccc} 
Spain & 7 & 15 & 1993 & 476 & 0.35 \\
\hline England & 8 & 5 & 1993 & 465 & 0.42 \\
\hline Italy & 9 & $\mathrm{n} / \mathrm{a}$ & 1992 & 411 & 0.11 \\
\hline Canada & 10 & 7 & 1993 & 325 & 0.05 \\
\hline Australia & 11 & 14 & 1995 & 302 & 0.05 \\
\hline India & 12 & 20 & 1995 & 231 & 0.03 \\
\hline The Netherlands & 13 & 1 & 1994 & 229 & 0.05 \\
\hline Sweden & 14 & 4 & 1993 & 216 & 0.31 \\
\hline Portugal & 15 & $\mathrm{n} / \mathrm{a}$ & 1993 & 182 & 0.08 \\
\hline Singapore & 16 & 2 & 1998 & 167 & 0.00 \\
\hline Brazil & 17 & 17 & 1998 & 163 & 0.09 \\
\hline Taiwan & 18 & $\mathrm{n} / \mathrm{a}$ & 1993 & 162 & 0.02 \\
\hline Switzerland & 19 & $\mathrm{n} / \mathrm{a}$ & 1997 & 97 & 0.00 \\
\hline Turkey & 20 & $\mathrm{n} / \mathrm{a}$ & 2005 & 96 & 0.00 \\
\hline
\end{tabular}

Table 2: Countries analyzed by CiteSpace and KPMG rankings

Source: prepared by the authors.

Note that the United States ranks first in number of publications and third in the KPMG analysis, which could be explained by the synergies of numerous stakeholders (e.g., academia, public organizations, automotive companies, technology companies), since according to the KPMG report, the US is ranked at the top of the technology and innovation pillar. It scored maximum or near-maximum ratings on industry partnerships, research and development hubs, AV technology company headquarters, investment, and world economic forum ratings for technology availability and capacity for innovation. Besides the highest number of publications $(3,078)$ and having the oldest publication in the analysis, the country has by far the greatest number of AV-related companies, with 163 headquarters (KPMG, 2018).

It is not only large companies driving the discussion on AVs in the USA, but startups like Faraday Future are also playing a role in imagining the applications of these vehicles (Gleave et al., 2016). Additionally, universities are contributing significantly to AV R\&D; for instance, Uber has collaborated with two institutions, the College of Optical Sciences at the University of Arizona and the University of Michigan (NBC, 2015). It is also important to highlight DARPA's Grand Challenge, which may also be a booster for American publications.

China, which ranked second in the number of publications $(1,484)$, aims to lead the race in terms of electric vehicles and AVs by 2030. In fact, the country has ambitious plans for AVs, expecting vehicles with "driver assistance" and "partial driving automation" to account for $50 \%$ of sales by 2020 , "conditional driving automation" cars $15 \%$ of sales by 2025, and, "high and full driving automation" vehicles 10\% of sales by 2030 (Dunne, 2016). Contrarily, China ranks $16^{\text {th }}$ in KPMG's report. In this context, the government could be one of the main stakeholders to develop the AVs in the country, although more accurate public mapping would help achieve AVs readiness (KPMG, 2018).

Although the Netherlands ranks $13^{\text {th }}$ in number of publications (229), the country is the indisputable leader in KPMG Index. The Dutch ecosystem for AVs is complete, providing the infrastructure, as well as a supportive government AV readiness model for other countries to follow, with excellent road and an already enthusiastic adoption of electric vehicles (KPMG, 2018).

Singapore holds the second position in KPMG report but ranks $16^{\text {th }}$ regarding publications (167). Singapore's 2017 amendment to its Road Traffic Act allowing selfdriving vehicles to be tested on public roads has helped the city state gain its high level of 
AV readiness and could explain the country's good position in KPMG's report. Moreover, the country tops two pillars of this index, "policy and legislation" and "consumer acceptance," and is second to the Netherlands in infrastructure (KPMG, 2018).

Besides the Netherlands, several European countries are taking significant steps to be at the forefront of this field's research, with nine out of the 20 countries that have published the most papers on the subject (Germany, France, Spain, the UK, Italy, Portugal, Sweden, the Netherlands, and Switzerland). The European Commission and other European bodies have demonstrated great interest in vehicle automation by funding a variety of research and innovation. One of the main areas was the development and implementation of driver assistance systems to improve driving safety (Gleave et al., 2016).

Particularly, German manufacturers are promoting full driving automation vehicles and are currently undertaking tests. OEMs' such as Audi, BMW, and Mercedes-Benz are active in this sector, leading experiments worldwide. The country ranks third when it comes to publications (643) and sixth in KPMG's readiness index.

When it comes to publication centrality, the UK has a predominant score $(0.42)$, followed by Spain (0.35), and Sweden (0.31). While USA and China, the most signified countries in number of publications, present a low influence in centrality score $(0.11$ and 0.08, respectively). The European Union influence could be responsible for the high centrality score of European countries. According to the European Commission (2017), it is time to put into practice the possibilities of AVs in real traffic conditions. The experience from some member states shall be used and test data should be exchanged. The use of other languages except English can explain the low centrality score in countries with higher publication numbers, such as China, South Korea, and Japan.

\section{In-depth analysis}

\section{Dual-map overlays}

For a broader view of the field's evolution, we carried out the CiteSpace dual-map overlay analysis. These interactive maps allow the exploration of how disciplines are related and how individual publications from an organization are distributed across a landscape (Chen \& Leydesdorff, 2014). The initial appearance of the user interface simultaneously shows citing and cited journal base maps. Each dot represents a journal, where the base map of 10,330 citing journals is on the left and the 10,253 cited journals are on the right. This layout reflects the similarity among journals based on data in Thomson Reuters' Journal Citation Report (Chen, 2016).

In this paper, two dual-maps overlays were drawn in Figure 4 (A) and (B). The methodological procedures for the construction of the dual-map overlay (A) use the same database as all other analyses in this paper (AVs), separating the curves by distinct colors. To contrast the results, we use the $z$-score option that converts the raw scores into a standard. As for the dual-map overlay (B), we use the AVs research database (highlighted in red); however, to draw a comparative analysis, we carried out a new database search, here named electric vehicles ${ }^{6}$ (highlighted in cyan), therefore adding a new overlay.

In Figure 4 (A), the evolutions in the field of the AVs can be observed. It is worth noting the predominant field of mathematics, system, and mathematical (MSM) evolves strongly (see the thickness of the curve indicated by this field) in terms of references cited, for the

\footnotetext{
${ }^{6}$ For electric vehicle data, the articles were searched on the WoS database in a single search using the Boolean operator "AND" and were selected by the following terms in the title, abstract, or keywords: electric_vehicle* AND car, for a total of 4,148 papers.
} 
most part, in systems computing, computer (SCC). Further, the MSM field evolves discreetly to economics, economic, and political (EEP), indicating that this field (EEP) within the AVs theme makes use of MSM in its publications. In addition, we noticed influences (even on a small scale) of publications in all other fields, corroborating with the assertion of the heterogeneity of publications on AVs.

As for Figure 4 (B), which includes the electric vehicles database (over the AVs database), we can see an alignment between the two themes. An overlap of the electric vehicles curve (cyan) over the AVs curve (red) of the publications on MSM is strongly evolving to SCC, as well as influences EEP. This fact shows that electric vehicles and AVs are aligned when it comes to academic influence. In other words, AV technologies can help enable a transition to electric and other alternative fuel vehicles (Anderson et al., 2014). These vehicles, fully or partially powered by electricity, would be able to travel the same range using smaller and cheaper batteries.

Additionally, Figure 4 (B) shows that electric vehicles have strong influence also from physics, material, and chemistry (PMC), with a strong evolution curve for PMC. This may indicate that the evolution of PMC within the theme of electric vehicles is still making significant use of the knowledge generated by the field itself. Furthermore, the Earth, geology, and geophysics field (EGG, on the right side) currently shows influences from different knowledge areas and is marked by an increasing number of publications (denoted by the large circle around it). This may be related to the growing trend towards cleaner and more sustainable energy, as well as environmental issues regarding electric vehicles and their positive impacts on the oil industry. 

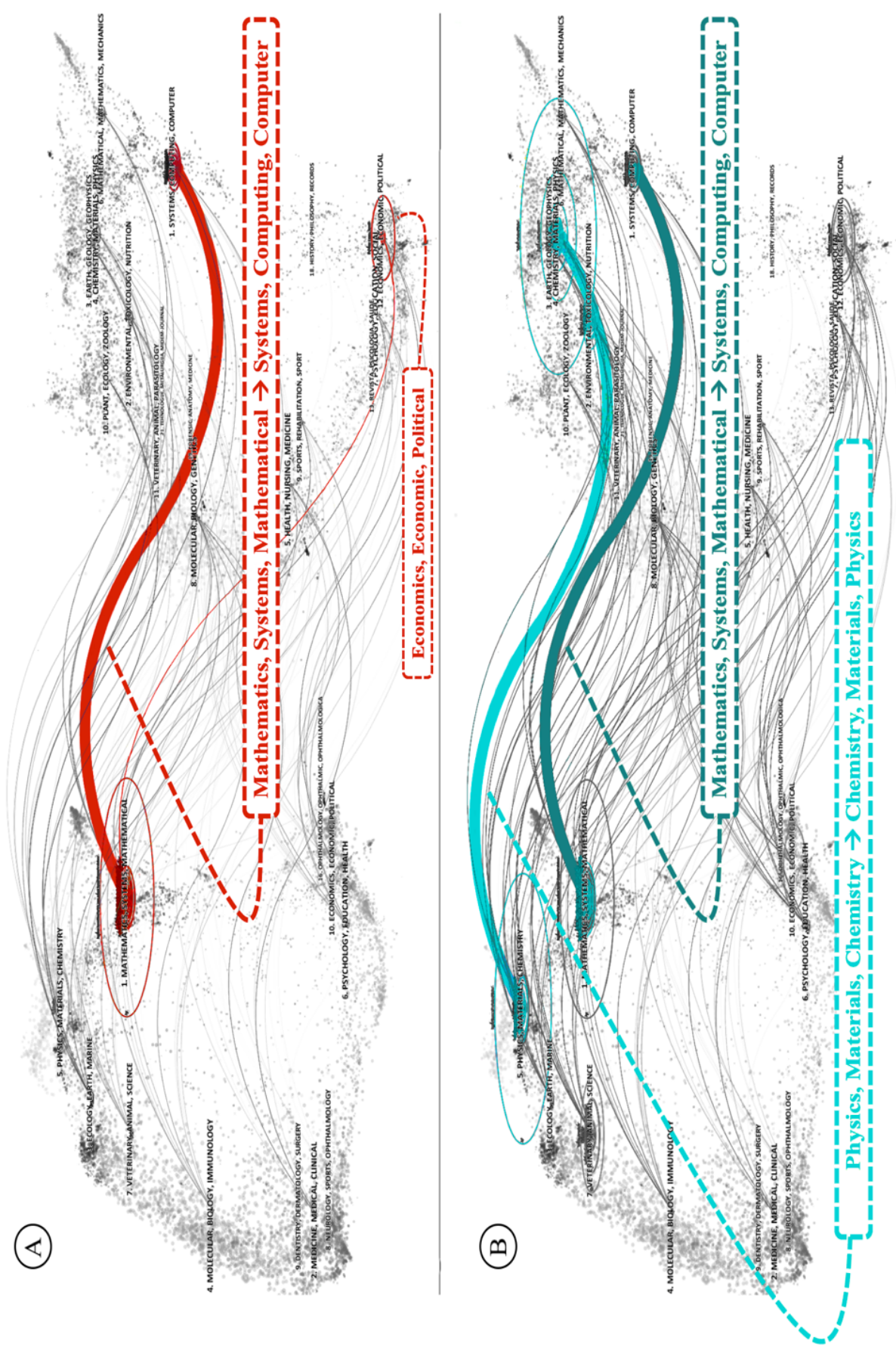

Fig. 4: Citation dual-map overlays of AVs and electric vehicles.

Source: prepared by the authors on CiteSpace. 


\section{Web of Science category analysis}

Figure 5 presents the top 20 categories from the total 96 in which the studies on AVs are anchored (demonstrating a multidisciplinarity in the field's knowledge development). However, more than half of the sampled papers $(53.49 \%)$ fit within the engineering category, $41.14 \%$ within computer science, $23.51 \%$ within transportation and automation control systems, and $16.26 \%$ within robotics, evidencing the technical aspects of the studies in this field. We highlight that each article can be listed within one or more WoS category, explaining why the total exceeds $100 \%$.

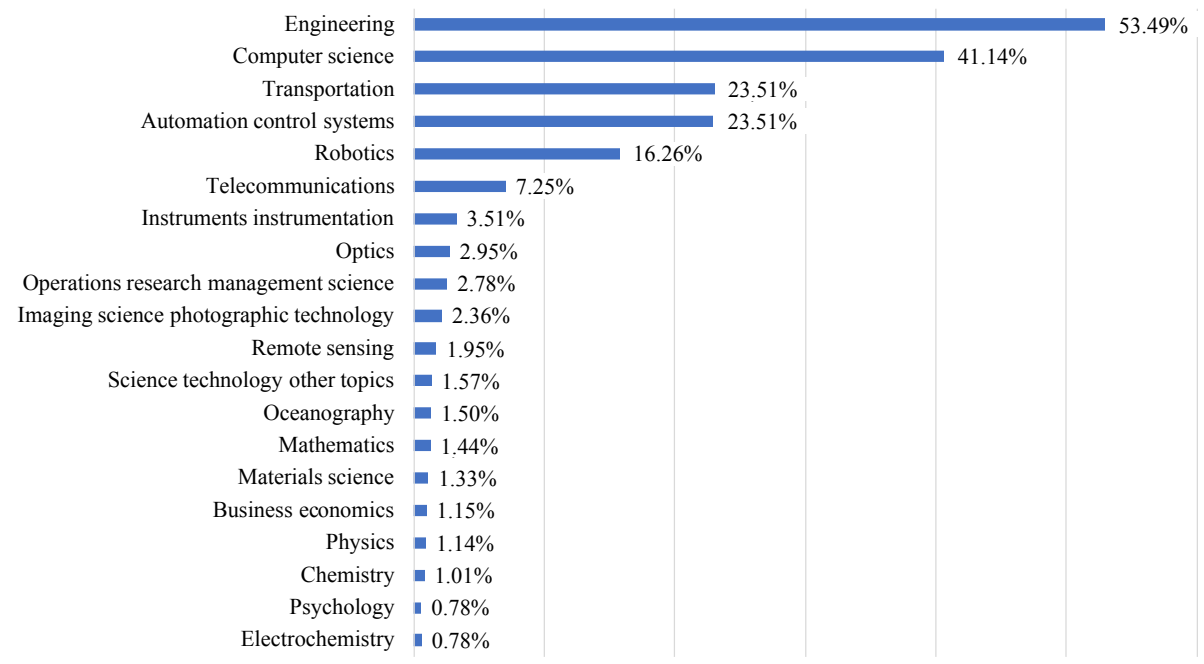

Fig. 5: Top 20 research categories

Source: prepared by the authors.

Furthermore, only three of the top twenty categories are non-technical-operational research management science $(2.72 \%)$, business economics $(1.08 \%)$, and psychology $(0.78 \%)$-which corroborates the aforementioned predominance of technical studies in the AV field.

Such a low incidence of business-related categories in relation to the other areas of knowledge demonstrates a possible mismatch between the technological evolution of the field and the businesses models and platforms necessary for the presence and consolidation of such vehicles on the market. As pointed out by Yun et al. (2016), the business model plays an extremely important role in the events that precede the advancement of AVs in society. Therefore, by increasing the level of the business model, even if the level of technology is not high, the size of the market increases through positive feedback (Yun et al., 2016; Shapiro \& Varian, 1999). This development can be achieved by the adoption of standards that organize innovations diffusion (Shapiro \& Varian, 1999) or by clusters of formed innovation (Zimmerman, 1995; Kokshagina, 2014).

Therefore, it is expected that the studies in business-related categories, as well as the social-related fields, are going to increase as the introduction of AV really becomes reality in the near future.

To analyze these, Figure 6 shows the categories' bursts, according to Kleinberg's burstdetection algorithm (Kleinberg, 2002). Chen (2006) reinforces that such an algorithm is adapted to identify emergent research-front concepts. To elucidate the use of such 
algorithms for the above categories, it is worth highlighting that "the burst-detection algorithm can be adapted for detecting sharp increases of interest in a specialty" (Chen, 2006, p. 364). Although Kleinberg (2002) states that the original algorithm was developed to detect the bursts of single words, "the algorithm is generic enough to be applied to a time series of multiword terms or citations of articles" (Chen, 2006, p. 364).

We notice that this scenario has been changing recently, since it is possible to observe, from 2015 onwards, a burst of categories that concern to non-technical aspects of AVs (Figure 6). These are social sciences, management, philosophy, business and economics, law, and urban studies, among others. That is, among the 35 categories that presented a burst of publications, $12(\sim 35 \%)$ were characterized by areas of applied social sciences and humanities. Rather than showing the evolution of the field, this analysis explains the main trends for future studies in the AV field.
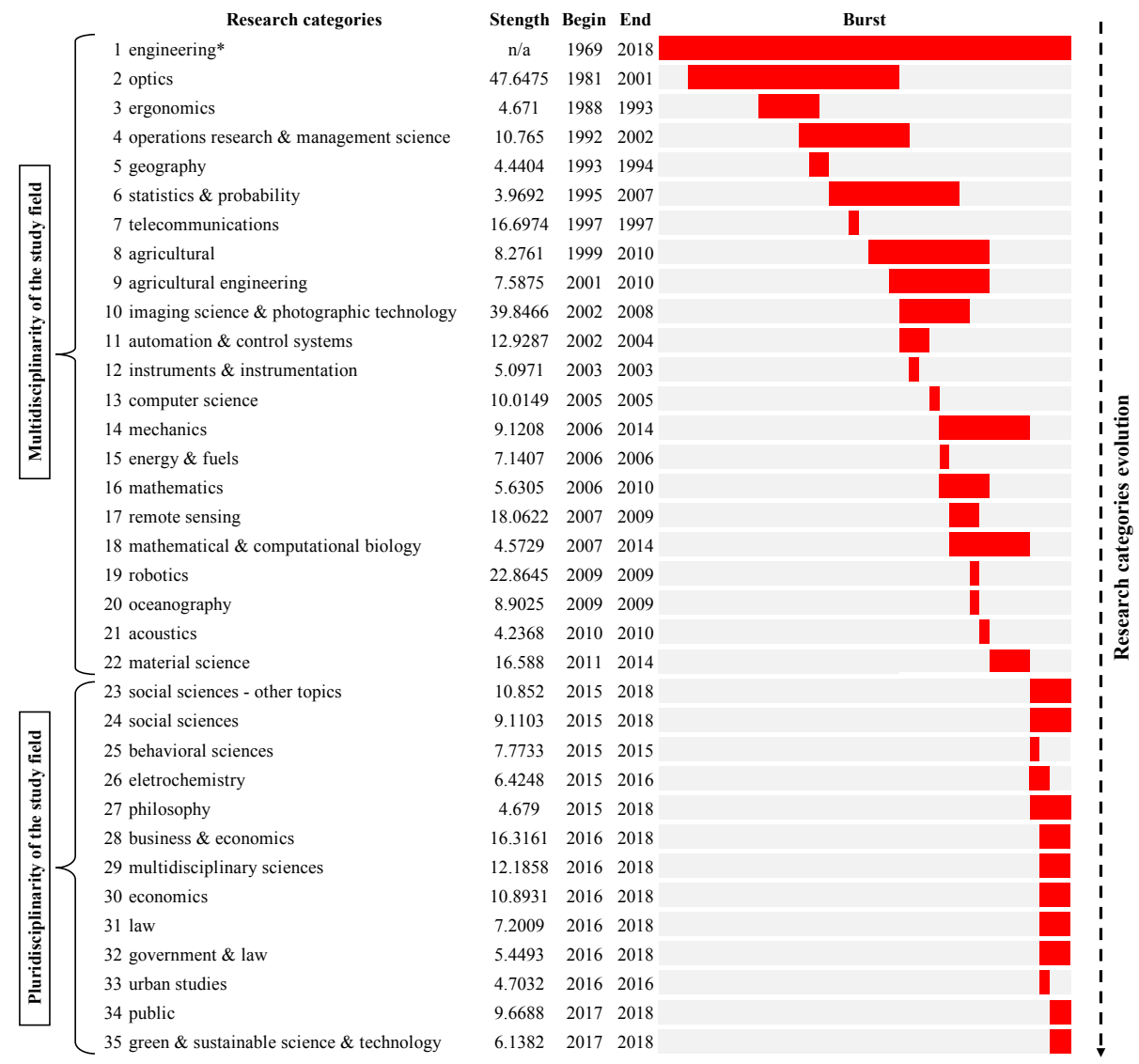

*Because of its relevance, the category of Engineering presents an uninterrupted burst.

Fig. 6 Categories' burst-detection based on WoS data.

Source: prepared by the authors on CiteSpace.

As observed from the number of papers per year analysis, there was an explosion of publications after 2012. During this period, there was a migration of common areas from multidisciplinary (common theme without relation nor cooperation among categories) to 
pluridisciplinary (common theme with relation and cooperation among categories). Thus, one can hypothesize that technical areas, such as engineering, computer science, and automation, seem to have reached a certain degree of maturity and present a constant variation in the number of publications. On the other hand, the discussions and studies extrapolating AVs technical aspects, by inserting them in a dynamic environment with several agents and implications, are far from being exhausted.

\section{Keywords analysis}

The keyword search on the 10,580 articles aimed at elucidating the main approaches in the field's evolution. In this sense, Figure 7 shows, chronologically, the 46 keywords with greater burst strength, according to Kleinberg's (2002) burst-detection algorithm. The first column displays the keywords; the second column shows the burst strength found by the algorithm, followed by the initial and final burst period; and finally, the corresponding burst time interval is highlighted by the red dashes.

To contextualize the observed results among keyword bursts, it is worth highlighting the historical moment at which DARPA's Grand Challenge was inserted in AV studies. We sought here to bring the discussion on bursts as close to reality as possible to consider DARPA as a watershed on AVs. As pointed out by Lima (2015), the 2004 and 2007 DARPA's Grand Challenges were responsible for leveraging the tests and advancements on AV R\&D. 

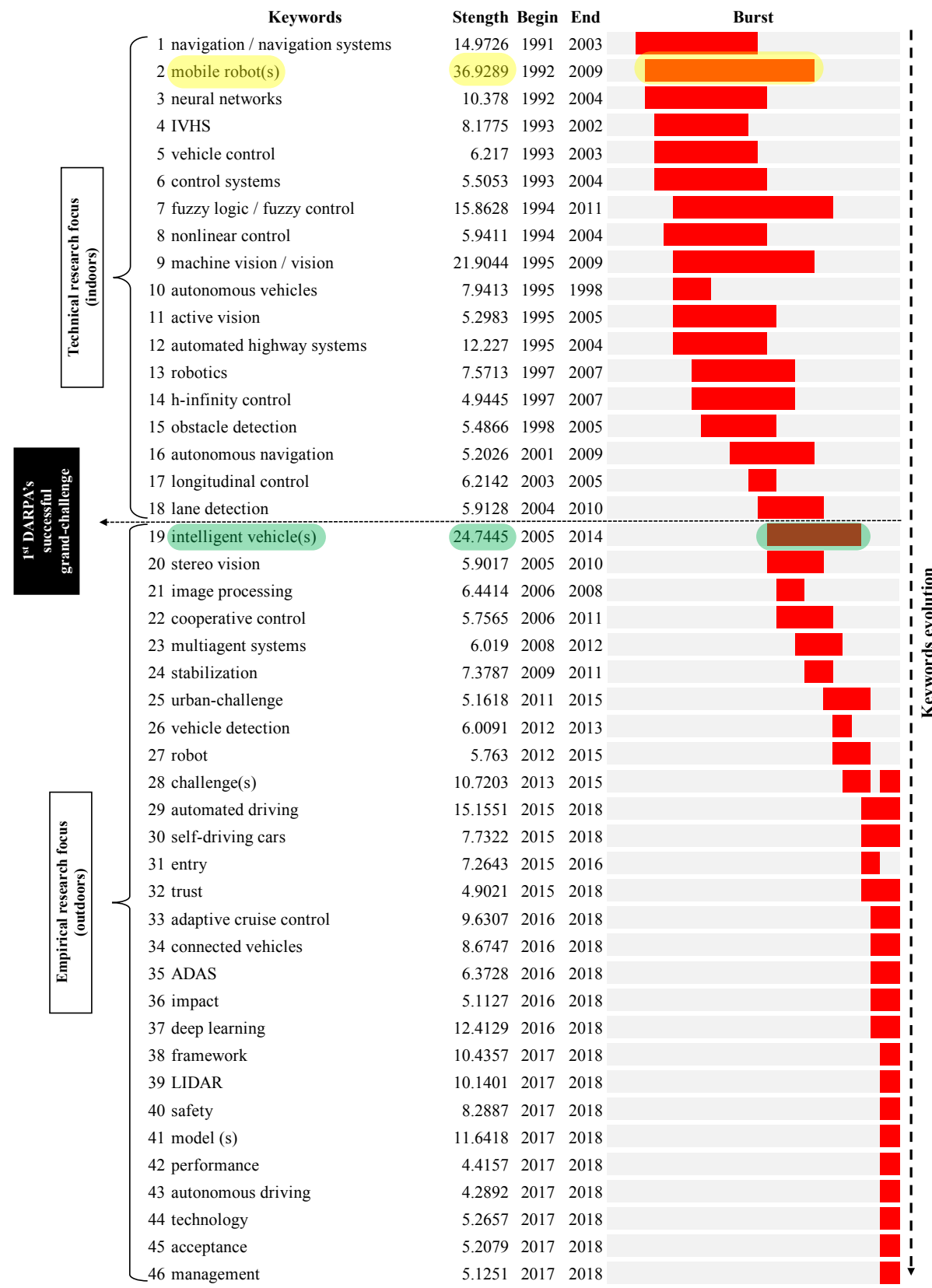

Fig. 7: Keywords' burst-detection based on WoS data.

Source: prepared by the authors on CiteSpace.

As per Figure 7, in the years before the challenges, there was a concentration of terms featured as more basic technical-focused regarding the conception of mobile robots, including AV based vehicles. Here, they are denominated as Technical Indoors Research 
Focus, with focus on the keyword "mobile robot(s)" (yellow griffins) - the term showed a strength of 36,9289 from 1992 to 2009, where, for approximately 17 years, the articles related to AVs sought to understand/relate to mobile robots.

Regarding the period after DARPA, here named Empirical Outdoors Research Focus, we observed a concern not only centered on the technical characteristics of AVs but also an approach to the systematization and empirical operationalization of vehicles beyond the laboratories. Highlighting (in green griffins) the term "intelligent vehicle(s)" with greater strength (24.7445) and time-span (2005 to 2014). The term "challenge(s)" also has significant strength (10.7203) and a five-year burst (from 2013 to 2015 and then from 2017 to 2018). This shows a strong relation between the publications and the challenges related to AV implementation, including the DARPA challenge.

It is also worth highlighting the terms with the most recent bursts (2017-2018), namely "framework," "LIDAR," "safety," "model(s)," "performance," "autonomous driving," "technology," "acceptance," and "management," which demonstrate AVs' exposure to reality. Finally, note the relationship between "management" and the studied topic, which is the most recent burst. Although the research field is almost 50 years old, only recently studies started focusing on the business impacts that AVs will have on the market.

\section{Concluding Remarks}

This work aimed at conducting a scientometric and bibliometric review to identify the main characteristics of the AV field, as well as its evolution, to highlight potential trends for future studies.

As for the descriptive analysis, there has been a great heterogeneity and a growing demand for this topic over the years. We observed, by the dispersion of authorship in the field, a non-fully constructed science, that a consolidated state-of-the-art on this subject has not yet been identified. This fact is also evidenced by the analysis of Price's elitism law. After 2012, the number of publications exceeded the trend line, showing an exponential growth of the field in recent years. This fact can be corroborated by analyzing the average science growth rate of around $8-9 \%$ per year, while the average growth rate of publications on AV in the analyzed period was 39\%. Regarding the higher number of publication sources, it was observed that only $0.70 \%$ of the sources are responsible for approximately $33 \%$ of the publications on the theme. Therefore, it is worth noting that the scope of AVs is still being widely discussed in congresses and conferences, showing that such research subject is far from being exhausted in academia.

It is worth noting that the academic production country ranking is far from KPMG's Readiness Index ranking (Table 2), due to the analyzed key performance factors. This also implies that the introduction of AVs on the market is highly locally oriented, indicating that many adaptations in technology as well as in business models must be addressed. The country analysis also demonstrates that the number of papers in the field is more representative in areas where public administration stimulated and attracted stakeholders, setting the conditions to undertake tests and authorizing the use of AVs on road infrastructures (e.g., USA, China, and the EU).

As for the in-depth analysis, the dual-map overlay analysis emphasizes the predominant evolution from MSM to SCC, but also indicates performance in all other emergent areas of the AVs field. The dual-map overlay has also demonstrated an alignment between the studies related to AV and electric vehicles, evidencing the industry paths for AVs cross those for electric vehicles. In 2018, there is a trend of exponential advances in electric vehicles, resulting in immediate advantages over traditional fossil fuel vehicles in mobility 
services. Consequently, there is a tendency that AVs might use electric powertrain technology as one of the possible sustainable engine sources in the future.

The multidisciplinarity is present in 96 areas of research (categories). Although there is a predominance of areas related to the technical evolution of AVs, we noted a growing presence of fields that include these vehicles. We believe that the maturity reached by the studies in technical fields, such as engineering, computer science, and automation, raised new questions about the insertion of this technology on the market, possible involved agents, and main impacts and implications that such vehicles will have on urban mobility.

Although there are studies on business, economics, and management, there is a slight evolution of these domains related to AVs. In this sense, the technological evolution of the area is evident. However, as in any other sector, it is necessary to understand broader aspects of this industry, such as the market factors surrounding them and other economic and managerial issues. The burst analysis of keywords corroborates the recent requirements of the field to extrapolate the technological areas, indicating market plans (e.g., "management" is the most recent keyword burst term). The historical moment at which DARPA's challenges were created, indicates that the publications post-DARPA move closer to the reality outside laboratories. Further, there is a consensus that technological factors are essential for the fields' evolution and should not be neglected. However, the other areas are also essential for the dissemination of the field and must follow the opportunities and requirements of this emerging issue.

To sum up, we observed a migration of the field from a multidisciplinary approach to pluridisciplinary one, with a greater number of studies converging to the latter. Additionally, we understand that the efforts regarding standardization of the term ADS (SAE, 2014, 2016) might contribute to achieve this pluridisciplinarity, since the unification of the theme will avoid misunderstandings and may enable clearer and more collaborative exchanges. However, there must be an impulse from academy on the use of this term.

Regarding trending topics, the results of the analysis of categories and keywords related to sustainability, public polices, liability and safety, as well as business issues, such as performance and business models, are characterized as relevant tendencies in AV research.

As limitations of this study, it is important to mention the use of the WoS as the only source for data collection, a fact that may not have considered other possible related works in this area. It is also worth mentioning that the terms used in the search could correspond to other types of vehicles (e.g., in chemistry, intelligent vehicles are used as a tool for medical research; in business, we found records of the terms being used for warehouses and logistics). We also highlight that, although the term ADS could solve these limitations, its use is still incipient (yielding in only 118 papers in our search).

The results of this study could contribute with useful insights and inputs to the emerging study areas on AVs. In-depth integrative studies are suggested to investigate what has been done in terms of public policies and law (e.g., government measures, tax incentives, regulatory aspects, liability), cyber-security (e.g., data privacy, data security, hacker attacks), car safety (e.g., analysis of probable crashes and accidents, probability of accidents on different automation levels), sustainability (e.g., environmental impact, ecological footprint, analysis of different fuel types and powertrains, AVs and responsible innovation approach), business-related issues (e.g., consumer acceptance, new market niches, new business models and platforms, impact of shared economy, emergency of MaaS schemes). Additionally, as an agenda for future studies, we suggest a more in-depth analysis of the individual publications per searched terms, as well as the sub-areas identified as trends in this paper. 


\section{References}

Anderson, J. M., Nidhi, K., Stanley, K. D., Sorensen, P., Samaras, C., \& Oluwatola, O. A. (2014). Autonomous vehicle technology: A guide for policymakers. Santa Monica: Rand Corporation.

Attias, D. (2017). The automobile world in a state of change: from the automobile to the concept of auto-mobility In: Attias, D. (2017). The Automobile Revolution: Towards a New ElectroMobility Paradigm. ( $1^{\text {st }}$ ed.). Gewerbestrasse (Switzerland): Springer International Publishing.

Börner, K., Chen, C., Boyack, K.W., (2003). Visualizing knowledge domains. Annual Review of Information Science \& Technology, 37(1), 179-255.

Bornmann, L. \& Mutz, R. (2015). Growth Rates of Modern Science: A Bibliometric Analysis Based on the Number of Publications and Cited References. Journal of the Association for Information Science and Technology, 66(11), 2215-2222.

Bradford, S. C. (1934). Sources of information on specific subjects. Engineering, 137, 85-86.

Cavazza, B.H., Gandia, R.M., Antonialli, F., Nicolaï, I., Zambalde, A.L., Sugano, J.Y., Miranda Neto, A. (2017). Management and Business of Autonomous Vehicles: a systematic integrative bibliographic review. Proceedings of the European Conference on Innovation and Entrepreneurship, [ECIE]. Paris, France, 12.

Chen, C. (2006). CiteSpace II: Detecting and visualizing emerging trends and transient patterns in scientific literature. Journal of the American Society for Information Science and Technology, 57(3), 359-377.

Chen, C. (2016) CiteSpace: a practical guide for mapping scientific literature. $\left(1^{\text {st }}\right.$ ed.). Hauppauge, NY: Nova Science Publishers.

Chen, C. and Paul, R.J. (2001) Visualizing a knowledge domain's intellectual structure. Computer, 34 (3), 65-71.

Chen, C., \& Leydesdorff, L. (2014). Patterns of connections and movements in dual-map overlays: A new method of publication portfolio analysis. Journal of the association for information science and technology, 65(2), 334-351.

Chen, C., Ibekwe - SanJuan, F., \& Hou, J. (2010). The structure and dynamics of cocitation clusters: A multiple - perspective cocitation analysis. Journal of the American Society for information Science and Technology, 61(7), 1386-1409.

Department for Transport. (2015). The Pathway to Driverless Car: A detailed review of regulations for automated vehicle technologies. Accessed in January, $20^{\text {th }}$ of 2017, from https://www.gov.uk/government/uploads/system/uploads/attachment_data/file/536365/driv erless-cars-proposals-for-adas-and_avts.pdf

Dunne, M. J. (2016, December 14) China Aims To Be No. 1 Globally In EVs, Autonomous Cars By 2030. Forbes. Retrieved March 9, 2017, from https://www.forbes.com/sites/michaeldunne/2016/12/14/chinas-automotive-2030-blueprintno-1-globally-in-evs-autonomous-cars/\#20056cd61c6e

European Commission (2017, March). European urban mobility: policy context. (European Union report). Retrieved February 23, 2018 from $<$ https://ec.europa.eu/transport/sites/transport/files/2017-sustainable-urban-mobility-policycontext.pdf $>$.

Fagnant, D.J., Kockelman, K. (2015). Preparing a nation for autonomous vehicles: opportunities, barriers and policy recommendations. Transportation Research Part A: Policy and Practice, $77,167-181$.

Frazzoli, E., Dahleh, M. A., Feron, E. (2002). Real-time motion planning for agile autonomous vehicles. Journal of Guidance, Control, and Dynamics, 25(1), 116-129.

Gleave, S. D., Frisoni, R., Dall'Oglio, A., Nelson, C., Long, J., Vollath, C. Ranghetti, D. \& McMinimy, S. (2016). Research for TRAN Committee - Self-piloted cars: The future of road transport? (Transport and Tourism), Brussels, BE, Policy Department Structural and Cohesion Policies, directorate-general for internal policies, European Parliament's Committee on Transport and Tourism. 
Grau, A. (2012). President, Icon Labs. Telephone Interview, October 12.

Greenhalgh, T. (1997). Papers that summarise other papers (systematic reviews and metaanalyses). BMJ: British Medical Journal, 315(7109), 665-675.

Hickey, J. (2012). Vice President, Vínsula. Telephone Interview, October 11.

Hucko, F. The development of autonomous vehicles. Aalborg University Copenhagen, 2017. Copenhagen: Denmark (Master Thesis).

Kleinberg, J. (2002, July). Bursty and hierarchical structure in streams. In Proceedings of the eighth ACM SIGKDD international conference on Knowledge discovery and data mining (pp. 91-101). ACM.

Kokshagina, O. (2014). Risk management in double unknown: theory, model and organization for the design of generic technologies (Doctoral dissertation, Ecole Nationale Supérieure des Mines de Paris).

KPMG International. (2018). Autonomous Vehicles Readiness Index. Available at: < https://assets.kpmg.com/content/dam/kpmg/nl/pdf/2018/sector/automotive/autonomousvehicles-readiness-index.pdf $>$ Access on 01/06/2018.

KPMG, CAR. (2012). Self-Driving Cars: The Next Revolution. Ann Arbor, MI.

Lima, D. A. (2015). Sensor-based navigation applied to intelligent electric vehicles. Doctoral thesis, Université De Technologie De Compiègne, Compiègne, France.

McKinsey \& Company. (2016). An integrated perspective on the future of mobility. United Kingdom, UK.

Milakis, D., van Arem, B., van Wee, B. (2017). Policy and society related implications of automated driving : a review of literature and directions for future research. Journal of Intelligent Transportation Systems: Technology, Planning, and Operations 21 (4), 324-348.

Mutz, F., Veronese, L. P., Oliveira-Santos, T., de Aguiar, E., Cheein, F. A. A., \& De Souza, A. F. (2016). Large-scale mapping in complex field scenarios using an autonomous car. Expert Systems with Applications, 46, 439-462.

Nascimento, S., Salvador, A., Vilicic, F. (2017, November). A era da autonomia. Revista Veja, 2554(44), 76-87.

NBC News (2015). Uber Working With University of Arizona to Create Self-Driving Cars. Accessed in January, 22 ${ }^{\text {th }}$ of 2017 , from http://www.nbcnews.com/tech/tech-news/uberworking-university-arizona-create-self-driving-cars-n415886

Palatnick, A. S., \& Inhelder, H. R. (1970). Automatic vehicle identification systems-Methods of approach. IEEE Transactions On Vehicular Technology, 19(1), 128-136.

Patel, V. J. (2018). Autonomous Cars Have a Clearer Path in Europe Than in America. Future Car - JPM Media Corporation. Retrieved on July 24, 2018, from: < http://www.futurecar.com/2288/Autonomous-Cars-Have-a-Clearer-Path-in-Europe-Thanin-America>.

Pollack, J., \& Adler, D. (2015). Emergent trends and passing fads in project management research: A scientometric analysis of changes in the field. International Journal of Project Management, 33(1), 236-248.

Pomerleau, D. and Jochem, T. (1996). Rapidly adapting machine vision for automated vehicle steering. IEEE Expert, 11(2):19-27.

Price, D. J. (1976). O desenvolvimento da cidadania: análises histórica, filosófica, sociológica e econômica. (Mathias. S, Trans.). Rio de Janeiro: Livros Teóricos e Científicos, 96. (Original title published in 1976)

Rifkin, J., (2011). The third industrial revolution: how lateral power is transforming energy, the economy, and the world. Macmillan

Roberts, A., \& Mathews, B. (1982). Charge-coupled device (CCD) camera/memory optimization for expendable autonomous vehicles. Optical Engineering, 21(2), 212354-212354.

SAE (2014). Levels of Driving Automation Are Defined In New SAE International Standard J3016, Society of Automotive Engineers. Retrieved on July 5, 2018, from: $<$ www.sae.org/misc/pdfs/automated_driving.pdf $>$. 
SAE International. (2016). Surface vehicle recommended practice: (R) Taxonomy and Definitions for Terms Related to Driving Automation Systems for On-Road Motor Vehicles. USA.

Schoitsch, E. (2016). Autonomous Vehicles and Automated Driving Status, Perspectives and Societal Impact. Information Technology, Society and Economy Strategic Cross-Influences (IDIMT-2016). 24th Interdisciplinary Information Management Talks, 45(1), 405-424.

Schwab, K. (2017). The fourth industrial revolution. Penguin UK.

Shapiro, C., \& Varian, H. R. (1999). The art of standards wars. California management review, 41(2), 8-32.

U.K. Department for Transport. (2015). The Pathway to Driverless Cars: a detailed review of regulations for automated vehicles technologies. U.K. Government. Retrieved February 26, 2018, from:

$<$ https://www.gov.uk/government/uploads/system/uploads/attachment_data/file/401565/pat hway-driverless-cars-main.pdf $>$.

Vasudevan, R. K., Ziatdinov, M., Chen, C., \& Kalinin, S. V. (2016). Analysis of citation networks as a new tool for scientific research. MRS Bulletin, 41(12), 1009-1016.

Weick, C.W., Jain, R.K. (2014). Rethinking industrial research, development and innovation in the 21st century. Technology in Society, 39, 119-116.

Yun, J. J., Won, D., Jeong, E., Park, K., Yang, J., \& Park, J. (2016). The relationship between technology, business model, and market in autonomous car and intelligent robot industries. Technological Forecasting and Social Change, 103, 142-155.

Zimmermann, J.B. (1995). Le concept de grappes technologiques. Un cadre formel, Revue économique, Volume 46, n5, pp. 1263-1295. 